\title{
Prävention von Verletzungen und Erkrankungen im OP
}

\author{
Klaus Dresing, Bianca Lumpp, Klaus Michael Stürmer
}

\section{Zusammenfassung}

Pflegekräfte und Operateure stehen täglich Gefahren im OP gegenüber. Risikopatienten mit viralen Infektionserkrankungen (Hepatitis B und C sowie HIV) stellen ein erhöhtes Ansteckungsrisiko dar. Die Zahl infizierter Patienten ist in der Klinik höher als die vom Robert-Koch-Institut (RKI) ermittelte Prävalenz: Das Personal im OP ist einer bis zu 6-mal höheren Prävalenz von HCV und 2,5 fach höheren von HIV ausgesetzt, als dies die epidemiologischen Zahlen ergeben. Die Infektion mit HBV, HCV und HIV kann fatale, ja letale Folgen haben. Für infiziertes Personal bedeutet eine Infektion und damit Übertragbarkeit auf Patienten häufig das Ende der operativen Tätigkeit. Verletzungen während der operativen Tätigkeit und bei der Entsorgung von scharfen Gegenständen und $\mathrm{Na}$ deln sind die häufigste Ursache von Verletzungen im OP. Deshalb muss es oberstes Gebot für alle im OP sein, alle Schutzmaßnahmen auszuschöpfen, diese Infektionen durch Patienten im OP zu vermeiden oder mindestens weit gehend zu minimieren. Folgende Sicherheitsregeln sollten beachtet werden:
- Schutzimpfung gegen HBV bei allen Mitarbeitern im OP

- Abklärung des Infektionsstatus des Verletzten

- Keine Nadeln, spitzen und scharfen Instrumente mit den Fingern fassen oder tasten

- Vorsicht bei Cerclagedrähten, abgekniffenen hervorstehenden Bohrdrähten,

- Vorsicht bei engem Operationsfeld

- Vorsicht bei verlängerten Operationszeiten

- Vorsicht bei entsicherten Bohrmaschinen

- Verwendung von vorgeschriebenen Abwurfbehältern

- Nicht in Abwurfbehältern blind suchen

- Verwendung doppelter bzw. Indikator-Handschuhsysteme

- In der Knochenchirurgie und Prothetik an Benutzung von Zwirnhandschuhen denken

- Verwendung von Augen- und Gesichtschutz

- Vorsicht beim Einsatz der Jet-Lavage

- Sofortmaßnahmen nach Verletzung ergreifen

\section{Einleitung}

Pflegekraft und Operateur sind während ihrer Tätigkeit im OP zahlreichen Gefahren ausgesetzt. Die invasive Natur von chirurgischen Eingriffen und die dafür notwendigen scharfen Instrumente beinhalten, dass sich alle Akteure während der Operationen der Gefahr aussetzen, sich selbst zu verletzen und dabei zu infizieren. Schätzungen der BGW gehen bei

OP-JOURNAL 2005; 21: 28-37

(c) Georg Thieme Verlag KG Stuttgart · New York rund 5 Mill. Versicherten von ca 1 Mill. Stich- und Schnittverletzungen im Jahr 2002 aus, von denen ca 28000 der BG gemeldet und 458 zur Anerkennung (HBV-, HCV- und HIV-Infektion) führten [38]. Potenziell besteht bei jeder Verletzung Infektionsgefahr für Operateur und Personal. HBV- und HCV- sowie HIV-Infektion sind die gravierenden Erkrankungen, die vom infizierten Patienten übertragen werden können. Für HBV gibt es einen Impfschutz, für die HCV und HIV-Infektion noch nicht. Die postexpositionellen Therapieverfahren sind sehr belastend und diffizil.
Umgekehrt können Operateure und Pflegekräfte, die sich bei ihrer Tätigkeit im OP selbst infiziert haben, ihre Patienten anstecken. Diesen Mitarbeitern droht als potenzieller Infektionsquelle Berufsverbot wie bereits ein höchstrichterliches Urteil aufzeigt. Die Serokonversion hat nicht nur erhebliche Auswirkungen auf Laufbahn und Zukunft des ärztlichen und OP-Personals selbst, sondern auch gravierende Auswirkungen auf die Familie.

\section{Epidemiologie und Hinweise}

HIV

Nach HIV-Infektion kommt es zunächst zu einer ausgeprägten Virämie. Die Antikörper können mittels HIV-PCR nachgewiesen werden. Um diese Serokonversion herum gelegen kommt es bei den Infizierten häufig zu Symptomen wie Fieber, Unwohlsein, Hautausschlägen, Lymphknotenschwellung und Halsaffektionen.

Für Deutschland gibt die WHO für 1999 eine Inzidenz für HIV-Infektionen mit 0,021\% an [76]. Das RKI gibt für 2002 die Inzidenz von 268,26/1 Mio. Einwohner $(0,0268 \%)$ an, wobei in den Großstädten die Inzidenz um Potenzen höher ist als in den Flächenstaaten und neuen Bundesländern.

Für einen Chirurgen beträgt die Wahrscheinlichkeit an HIV während seiner etwa 35 Berufsjahre zu erkranken $1: 1500$ [55], in Italien wird das Risiko auf $0,54 \%$ in einem Chirurgenleben geschätzt [60]. In den USA wird die Seroprävalenz der Patienten für HIV in Akutkrankenhäusern zwischen 0,2 bis $14,2 \%$ eingestuft, wobei Männer zwischen 25 und 44 Jahren und Drogenmilieu auffallen [6,33]. Mitte 1999 waren in den USA 191 Personen gemeldet, die durch beruflichen Kontakt HIV infiziert waren [12]. In den USA wird von ca. 500000 perkutanen Kontaminationen beim ärztlichen Personal ausgegangen, von denen ca. 
5000 mit HIV-infektiösem Blut in Kontakt kommen können. Eine einzige Nadelstichverletzung von einem seropositiven Patienten bedeutet für den Operateur ein Risiko der Serokonversion von $1: 250$, wobei die Serokonversion über das Berufsleben des Chirurgen kumulativ auf 1 bis $10 \%$ geschätzt wird $[48,46]$. Das mittlere Risiko einer HIV-Übertragung wird auf 0,3\% geschätzt, wobei das Risiko bei größerer Menge übertragenen Blutes und/oder mit der Viruslast steigt [5]. Die Übertragungswahrscheinlichkeit wird höher mit größeren Instrumenten und tieferer Eindringtiefe. Die Infektionswahrscheinlichkeit nach Schleimhautexposition wird auf $0,009 \%$ geschätzt [31].

\section{Hepatitis B}

Die Inkubationszeit beträgt 40 - 180 Tage. Etwa 30\% der Infizierten bleiben ohne Symptome und dies ist ein Problem im Erkennen der Infektion beim zu operierenden Patienten, ein Drittel hat grippeähnliche Beschwerden und ein Drittel bekommt einen Ikterus. In 0,1-1\% verläuft die HBV fulminant und tödlich. $90 \%$ der Infizierten heilen aus, 10\% bleiben chronische Virusträger, von diesen sterben etwa $20 \%$ an Leberzirrhose oder Leberzellkarzinom.

Übertragungen können ausgehen von Patienten bei denen HBsAg nachgewiesen wurde, sei es mit akuter oder chronischer Infektion [6]. Es besteht für einen operativ tätigen Arzt das Risiko, sich einmal während des Berufslebens an HBV zu infizieren [55] bzw. in 42,7\% in Italien [60]. Die Wahrscheinlichkeit einer HBV-Übertragung nach einer beruflichen Exposition ist abhängig von der Konzentration des Virus in der übertragenen Flüssigkeit, der Menge und dem Übertragungsweg (perkutan vs. Schleimhaut) [6]. HBV wird in Blut und seröser Flüssigkeit in hohen Titern nachgewiesen. In Speichel ist er normalerweise niedriger. HBV hat eine hohe Übertragungswahrscheinlichkeit bei Inokkulation. Nach einer Nadelstichverletzung mit HBV-kontaminiertem Blut von einem HbeAg-Träger wird die Übertragungswahrscheinlichkeit mit mehr als $30 \%$, bei negativem HbeAg unter $6 \%$ angegeben [24]. Lt. RKI liegt die Inzidenz für akute HBV in Deutschland 2002 bei $0,017 \%$. Lt. Statischem Bundesamt (2003) liegt die Anzahl der nach BseuchG gemeldeten Fälle für $\mathrm{HBV}$ im früheren Bundesgebiet und Ost-Berlin bei $0,064 \%$, in den neuen Bundesländern bei $0,017 \%$. Die in einer prospektiven Screeningstudie gefundenen Prävalenz- werte für HBV mit $0,08 \%$ liegen in etwa auf dem Niveau, das vom RKI für Niedersachsen angegeben wird [19].

Mit der Zahl der Berufsjahre steigt auch die Durchseuchung beim Personal. Die Seroprävalenz unter dem medizinischen Personal für HBV ist direkt proportional zur Beschäftigungsdauer [57,66] und abhängig vom Risikopotenzial der Tätigkeit.

Die aktive Immunisierung bietet den sichersten Schutz vor einer Hepatitis-B-Virusinfektion. Die Krankenhausträger müssen den Mitarbietern, die Umgang mit Blut oder Blutprodukten haben, somit alle im OP-Tätigen, einen kostenlosen Impfschutz ermöglichen [82].

Die aktive Immunisierung bietet den sichersten Schutz vor einer Hepatitis-B-Virusinfektion.

\section{Hepatitis C}

Nur $10 \%$ der HCV Infizierten entwickelt einen Ikterus. Nach etwa 3-10 Wochen treten Symptome auf: ca. $85 \%$ der Infizierten entwickeln eine chronisch, persitierende oder agressive Hepatitis. Unbehandelt entwickeln 5-30\% eine Leberzirrhose oder ein Leberzellkarzinom.

HCV wird durch Blut und Blutprodukte und auch durch perkutane Exposition übertragen. Die Übertragungswahrscheinlichkeit kann abhängig sein von der Art und Größe der Inokulation, dem Übertragungsweg, dem Titer, aber verlässliche Daten liegen nicht vor [6]. Weder die Präsenz von Akn noch von HCVRNA ist ein direktes Maß für die Infektiösität [6]. Die Inzidenz für HCV-Serokonversion ist deutlich niedriger als für HBV und wird mit durchschnittlich 1,8\% angegeben $[1,2,11]$.

\section{Ca. 330000 Personen in Deutschland sind} mit dem Hepatitis-C-Virus infiziert $(0,4 \%)$, davon sind ca. $84 \%$ entsprechend ca. 275000 Virusträger [70]. Andere Autoren gehen von einer höheren Prävalenz von bis zu $0,7 \%$ entsprechend 400000 bis 500000 Virusträgern aus [54]. Die Prävalenz variiert hoch unter verschiedenen Bevölkerungsgruppen. Anti-HCV-Seroprävalenz-Werte bei Krankenhauspatienten werden zwischen 2 bis $18 \%$ in Nordamerika angegeben $[36,44]$. In Deutschland wird die Prävalenzrate für HCV auf 0,63\% in der Erwachsenenbevölkerung geschätzt, wobei die Werte mit dem Alter und für das weibliche Geschlecht steigen
[54]. Große Unterschiede in den HCVPrävalenzen finden sich bei verschiedenen Risikogruppen.: Hämophile $87 \%$, Fixer $79 \%$, Vielfachtransfundierte $18 \%$, bei Transplantierten $17 \%$, bei Dialysepatienten $8 \%$, bei Prostituierten $1,4 \%$ und bei Personal im Krankenhaus 0,8\% [78]. Im Jahr 2002 wird die Inzidenz der Hepatitis-C-Erstdiagnosen für Deutschland mit $0,08 \%$ angegeben [65]. Hierbei sind Männer häufiger betroffen als Frauen. Angehörige aus der Drogenszene stellen das Hauptkontingent der Neu-Infizierten $[1,80]$, von ihnen sind 36 bis $95 \%$ HCV positiv [36]. Bei unfallchirurgischen Notfallpatienten liegt die HCV-Durchseuchung um den Faktor 4 - 6 höher als vom RKI angeben [19].

Chirurgen haben ein Risiko zwischen 1,4 und $34,8 \%$ eine HCV-Infektion zu erleiden, die übrigen Ärzte von $1 \%$ über einen Lebensarbeitzeitraum von 35 Jahren $[60,74]$. Die Durchseuchungsrate mit HCV ist für medizinisches Personal nicht signifikant höher als in der Normalbevölkerung [42].

\section{Risiko „Operationssaal“}

Die Übertragung von pathologischen Blutkeimen erfolgt hauptsächlich perkutan oder durch Schleimhautexposition mit Blut oder Körperflüssigkeiten infizierter Patienten [6]. Die berufliche Exposition kann in einer Übertragung von HIV, HBV oder HCV durch Verletzungen mit Nadelstich, scharfen Instrumenten und scharfkantigen Knochenfragmenten bestehen. Auch kann über Nasen-, Augenund Mundschleimhaut eine Übertragung eintreten. Untersuchungen zeigen, dass häufig das Pflegepersonal mehr als das ärztliche Personal betroffen ist, s. u. Maßnahmen zur Sicherheit und zum Gesundheitsschutz der Beschäftigten im Umgang mit biologischen Arbeitsstoffen sind in der BiostoffV festgelegt, die für den Bereich des Gesundheitswesens durch die Technische Regel für Biologische Arbeitsstoffe (TRBA 250) konkretisiert wird [21].

Operieren und Instrumentieren wird als Schutzstufe 2 eingestuft, da es sich hier um Tätigkeiten handelt, bei denen es regelmäßig und in größerem Umfang zum Kontakt mit Körperflüssigkeiten, -geweben und -ausscheidungen kommen kann [21]. Die Häufigkeit des Kontakts variiert je nach chirurgischer Disziplin und Tätigkeit zwischen 1,3 und 15,4\% pro operativem Eingriff [6]. Ärzte und Pflege im Notfallbereich und damit auch im Operationssaal sind den Gefah- 
ren mehr ausgesetzt, als andere Fachbereiche, jedoch hängt die Inzidenz sehr vom behandelten Patientenklientel ab [18]. In einer Multicenterstudie in Italien konnten in 9,2\% von 15375 Operationen Kontakt mit Blut oder Körperflüssigkeiten nachgewiesen werden, in $2 \%$ Hautperforationen oder Schleimhautkontamination [60]. Das Risiko des Blutkontaktes steigt mit einem intraoperativen Blutverlust größer $250 \mathrm{ml}$, einer Operationsdauer über einer Stunde und bei Notfallmaßnahmen [56]. Am höchsten ist das Risiko bei einer Operationsdauer von mehr als 3 Stunden [23]. Vorsichtsmaßnahmen sind der sicherste Weg sich vor Infektion zu schützen [75].

\section{Schutzmaßnahmen für Pflege und Operateur}

\section{Impfung}

Operateur und Pflegepersonal müssen sich gegen HCV-, HBV- und HIV-Kontamination schützen. Verschiedene Maßnahmen kommen infrage. Nur für HBV besteht die Möglichkeit der Prophylaxe durch Immunisierung mittels Impfung $[21,35]$.

Jeder Mitarbeiter im OP sollte sich prophylaktisch impfen lassen!

Eine Impfpflicht besteht in Deutschland ebenso wie in den USA, Kanada oder England jedoch nicht [29]. Bei nicht ausreichendem Impfschutz muss im Verletzungsfall passiv geimpft werden [82], s.u.

\section{Patienten-Screening}

Entscheidend für das operative Vorgehen ist häufig der Infektionsstatus des Verletzten. Hierzu erforderlich sind Screeningtests, die in kurzer Zeit Ergebnisse liefern. Bei der notfallmäßigen Versorgung auch von Polytraumatisierten kann nicht auf einen Test gewartet werden, der erst nach 2-3 Tagen vorliegt. Es gibt heute auf dem Markt Schnelltests, die 30-50 Minuten nach Eintreffen des Patienten (Analysenzeit inkl. Transport) Ergebnisse liefern [19]. Mit diesem Zeitfenster ist der Infektionsstatus normalerweise vor der operativen Maßnahme dem OP-Team bekannt. Grenzbefunde werden von den Operateuren zunächst behandelt wie ein positives Ergebnis [19]. In der prospektiven Studie (EBM IIa) konnte gezeigt werden, dass die Verletzten großes Verständnis für das Screening zeigen. Diese positive Einstellung gibt es auch bei Patienten, die Eigen- blutspende vor elektiven Operationen leisten [49]. Bei bewusstlosen Patienten wurde von deren Einverständnis ausgegangen. LaPorte und Mitarbeiter fanden in Baltimore (USA) bei 2727 Patienten, die sich freiwillig vor elektiven orthopädischen Operationen auf HIV testen ließen, in 99,7\% ein negatives HIV-Testergebnis. Sie leiteten aus ihren Ergebnissen $\mathrm{ab}$, dass mit diesem Screening der Chirurg und das Personal vor Hochrisiko-Patienten gewarnt wird, die Patientenversorgung nicht leidet und das Krankenhaus in die Lage versetzt wird, intensivere Vorsichtsmaßnahmen im Operationssaal zu ergreifen, um das Infektionsrisiko des Chirurgen- und Pflegeteams zu minimieren [41]. Ähnlich argumentieren Mineiro et al. [50], die aus ihren Ergebnissen bei 288 orthopädischen Patienten (1,4\% HBsAg, 3,1\% HCV und 1,75\% HIV-Infektionen) ableiten, dass bei orthopädischen Patienten eine generelle Infektionskontrolle erfolgen müsse. Der Operateur kann so je nach Infektionsstatus sein operatives Vorgehen umstellen. Nach bekannt werden des Infektionsstatus kann das Operationsmanagement dem Infektionsstatus angepasst werden. In einer Studie [19] wurde bei 13 Patienten das Operationsregime geändert. 9-mal wurde auf die geplante Jet-Lavage verzichtet, 2-mal auf eine minimal-invasive Osteosynthesetechnik mit durchgeschobener Platte, einmal von der internen auf externe Osteosynthese umgestiegen, einmal konservativ statt operativ behandelt. Eine systematische Testung wird nicht von allen empfohlen [35]. Eine gezielte HIV-Serologie wird hingegen gefordert [35]. Die Kosten des Screeningtests von knapp $32 €$ pro Patient verglichen mit den Kosten der Therapie bei HIV- oder HBV-Exposition erscheinen vernachlässigbar gering [19].

\section{Operationsablauf - Zusammenspiel zwischen Pflege und Operateur}

Regelmäßige Schulung aller Mitarbeiter im OP über Präventionsmaßnahmen, Hygiene und Risikoanalysen über die $\mathrm{Ge}$ fährdung durch blutübertragbare Infektionen ist eine wesentliche präventive Maßnahme. Denn insbesondere das Pflegepersonal ist bei potenziell infektiösen Prozeduren einem höheren Risiko als der Chirurg ausgesetzt [59]. Das OPTeam benötigt Informationen über den möglichen Infektionsstatus des Patienten, um das Gefährdungspotenzial gering zu halten [19]. Wichtig ist bei allen Operationen das abgestimmte Zusammenspiel zwischen OP- und ärztlichem Perso- nal. Beide sollten nicht parallel scharfe Instrumente anfassen [60]. Wichtig ist auch bei Hochrisikopatienten immer der Blickkontakt zwischen Operateur und Schwester vor und bei der Übergabe von Instrumenten. Besser ist, dass sich der Operateur so weit wie möglich bei scharfen Instrumenten selbst bedient [35], auch wenn dies gegen herkömmliche Gewohnheiten spricht. Die geforderte No-touch-Technik, wie sie für den Laparotomieverschluss gefordert wird $[7,15]$, ist bei vielen Eingriffen in der Unfallchirurgie und Orthopädie nicht einzuhalten. Bei einer Azetabulumfrakur kann der untersuchende Finger Stufen verifizieren, ohne dass weit freigelegt wird. Das Einsetzen von Haken und Retraktoren erfordert häufig zuerst die digitale Untersuchung bevor diese Instrumente ohne Schädigung z. B. von nervalen Strukturen eingesetzt werden können. Liegt der Nachweis einer Hepatitis- oder HIVInfektion zum Zeitpunkt der Operation vor, kann und muss der Operateur auf diese Maßnahmen verzichten. Die Abwägung eines evtl. besseren Operationsergebnisses gegenüber dem potenziellen Risiko einer Verletzung und Infektion

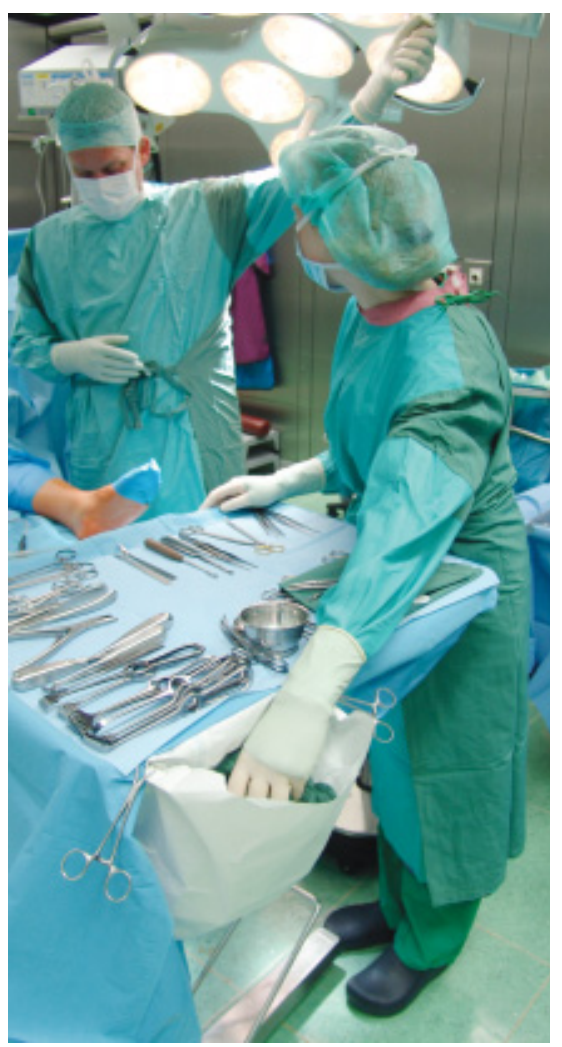

Abb.1 In Abwurftüten direkt am Instrumentiertisch dürfen keine scharfen Dinge abgelegt werden. In diesen darf weder blind abgelegt, noch blind gesucht werden. Die Verletzungsgefahr ist unkontrollierbar. 


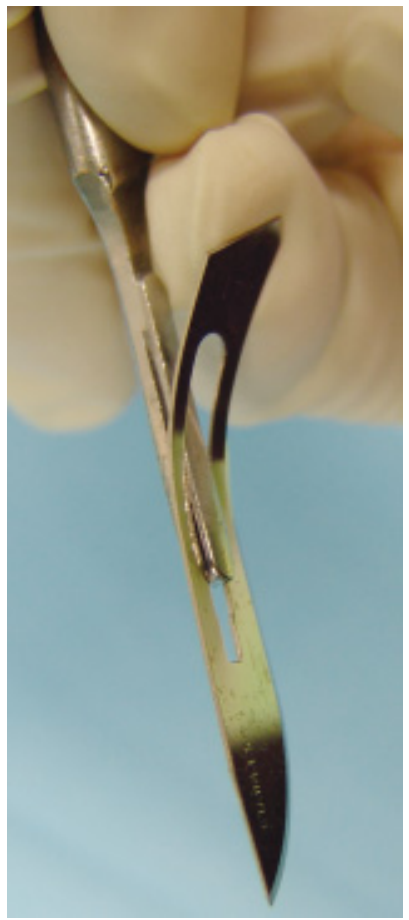

Abb. 2 Der Wechsel der Skalpellklinge mit den Fingern beinhaltet ein hohes Verletzungsrisiko. Die Klinge sollte mit einer Klemme entfernt werden.

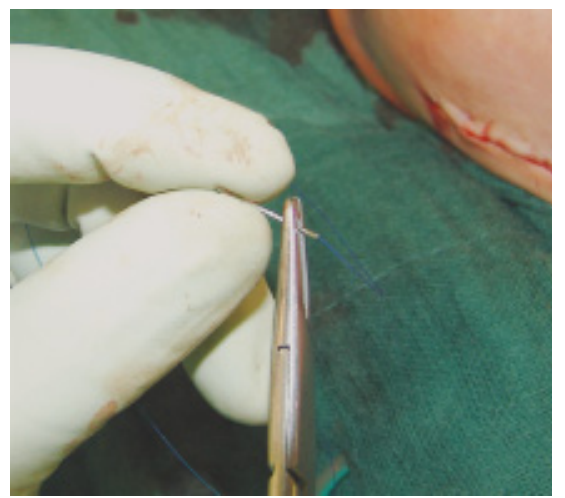

Abb.3 Das Einspannen der Nadel ist bei den Instrumentierenden die häufigste Verletzungsart. Bei Nadeln mit Federöhr oder bei Periostnadeln ist besondere Vorsicht geboten. Atraumatische Nadeln sollten aus der Packung mit dem Nadelhalter entnommen und vom Operateur ebenfalls nicht mit den Fingern gehändelt werden.

wird zulasten des Operationsergebnisses fallen.

Im OP sollte immer versucht werden, sicher mit sicheren Produkten zu arbeiten [82,35]. Spitze und scharfe Gegenstände müssen von Beginn bis zur Entsorgung vorsichtig gehandelt werden. Während der Operationshektik sollte nicht in Abfalltüten gesucht werden, da die Verlet-

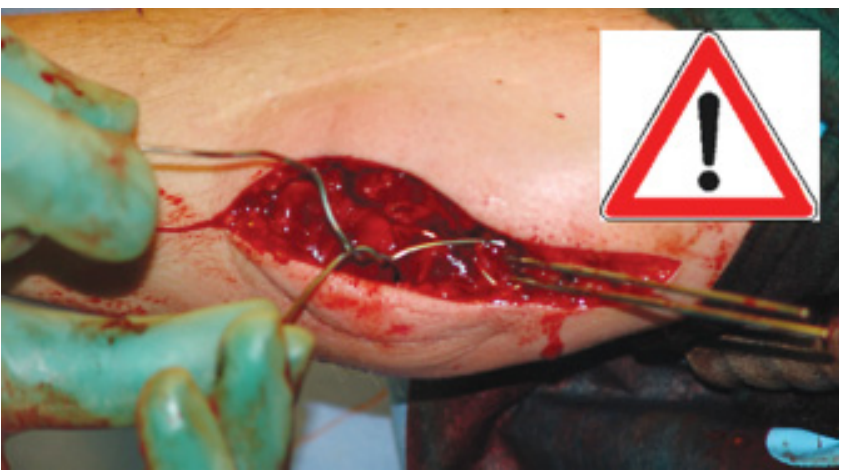

Abb. 4 Beim Führen von Cerclagedrähten um oder durch den Knochen besteht für den Operateur eine erhöhte Verletzungsgefahr. Bei bekannter Hepatitis- oder HIV-Infektion sollten zusätzlich Zwirnhandschuhe getragen werden.

zungsgefahr zu groß ist (Abb.1). Es sollte geprüft werden, ob mehr nicht gefährdende Instrumente eingesetzt werden können. Es sollten möglichst Instrumente und nicht die Finger $[14,15,30,51]$ eingesetzt werden, wenn scharfe Gegenstände gehalten werden müssen. Benutzte Skalpellklingen sollten nicht per Hand gewechselt werden (Abb.2). Vorsicht bei der Exploration verloren gegangener $\mathrm{Na}$ deln im Gewebe. Besser Retraktoren und Haken benutzen als die Finger, um Gewebe wegzuhalten. Cerclagedrähte stellen eine große Verletzungsgefahr dar. Hier sollten zusätzlich Stoffhandschuhe bei Risikopatienten verwendet werden (Abb.3). Schutzkappen sollten auf verwendete Kanülen und auch Skalpelle nicht wieder zurückgesteckt werden (Recapping), da ein hohes Verletzungsrisiko besteht. Nadeln möglichst nicht mit den Fingern annehmen (Abb.4). Bohrmaschinen sollten zwischen den Arbeitsvorgängen gesichert gelagert werden. Unabsichtlich anlaufende Bohrmaschinen führen zu Verletzungen (Abb.5). Die Berufsgenossenschaft (BGW) hat eine Liste sicherer Produkte zusammengetragen, die von Kanülen über Skalpelle bis zu Indikatorhandschuhen reicht [7]. Auch die SUVA stellt Produkte zusammen [35].

Auch perioperative Maßnahmen wie die Jet-Lavage bei infizierten oder verschmutzten Wunden wird unterbleiben müssen mit dem evtl. erhöhten Risiko eines posttraumatischen Infektes, da eine erhebliche Anzahl von Aerosolen im OP verteilt wird und damit der Schleimhautkontakt gegeben ist (Abb. 6). Lt. TBR 250 sollen alle eingesetzten Verfahren so erfolgen, dass die Bildung von Aerosolen minimiert wird [21].

Vorsicht mit dem Einsatz der Jet-Lavage bei Risikopatienten!

Es sollte jedem im OP klar sein, aber es wird immer wieder beobachtet: Mitarbeiter im OP dürfen an Arbeitsplätzen,

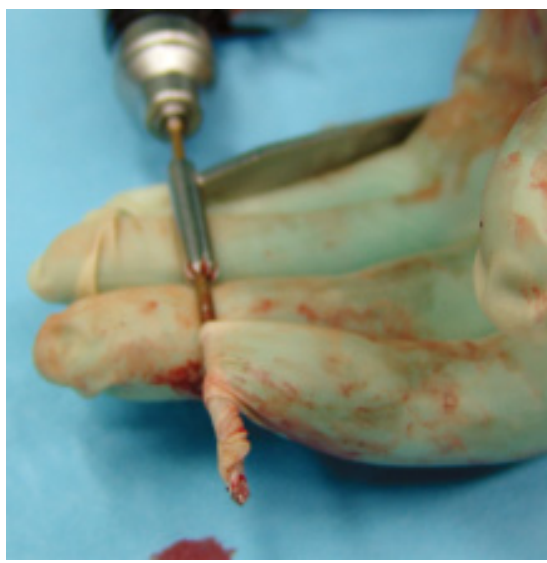

Abb. 5 Bohrmaschinen sind nach der Benutzung zu arretieren, damit es nicht zu ungewolltem Berühren der Schalter kommt und damit zu Verletzungen. In diesem Fall hat der Bohrer den äußeren Handschuh aufgewickelt.

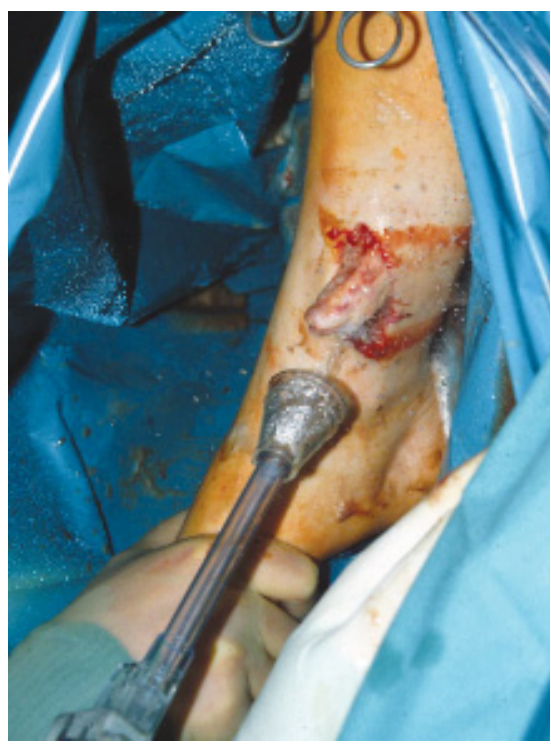

Abb. 6 Die Jet-Lavage ist ideal zur Säuberung von verschmutzten Wunden oder im Rahmen von Second-look-Operationen. Durch die starke Aerosol-Bildung darf die Jet-Lavage bei bekannter HBV-, HCV- oder HIV-Infektion nicht eingesetzt werden, da durch die Verteilung im gesamten OP die Kontamination der Schleimhäute stark begünstigt wird. 
an denen die Gefahr einer Kontamination besteht, keine Nahrungs- und Genussmittel zu sich nehmen oder lagern [21].

\section{Entsorgung}

Ein besonderes Risiko stellt die Aufbereitung der Instrumente für die Reinigung dar, da hier die Instrumente noch mit Blut und Körpermaterial kontaminiert sind und das Verletzungsrisiko besonders hoch ist $[21,35]$. Hierbei ist besondere Vorsicht geboten [21]:

- Einmalmaterial wird am Ende der OP mit Hilfsmitteln aus den Sieben entfernt

- Skalpellklingen, Nadeln und Kanülen sind mit Hilfsmitteln zu entfernen

- Spitze und scharfe Instrumente sind separat auf einem Sieb oder in einer Nierenschale abzulegen

- Alle manuell aufzubereitenden Maschinen sind gesondert zu behandeln, Aufsätze (Bohrer, Fräser) sind zu entfernen

- Ein Verheddern von Schläuchen und kabeln ist zu verhindern.

Geeignete bruch- und durchsichere Abfallbehälter sind zu verwenden und verschlossen zu entsorgen [82].

\section{Perforationen der Haut und deren Prophylaxe}

Operateur und Pflegepersonal müssen sich der Gefahr, der sie täglich ausgesetzt sind, immer wieder bei ihrem Tun erinnern. Verschiedene Faktoren beeinflussen die Gefahr der Kontamination. Das größte Risiko sind perforierende Verletzungen, die normalerweise durch Vorsichtsmaßnahmen nicht sicher verhindert werden können. Der Operateur muss sich diese Gefahr immer vergegenwärtigen. Die Perforationshäufigkeit und damit potenzielle Verletzungsgefahr wird häufig unterschätzt. Je tiefer das Operazionsgebiet, desto größer ist die Gefahr der Kontamination [10,9]. Die Gefahr ist bei Unfall- und Notfalleingriffen in der Knochenchirurgie, bei hohem Blutverlust, langen Operationszeiten und bei Manipulationen von Gewebe mit der Hand während der Naht besonders hoch $[59,60]$. Persönliche Schutzeinrichtungen sollen im Krankenhaus dem Personal nicht nur im OP zur Verfügung stehen [82,21], Details s. [21]. Die Schutzmaßnahmen gliedern sich in technische, organisatorische, personenbezogene und arbeitsmedizinische Maßnahmen [35].

\section{Schutz durch Handschuhe}

Nach der hygienischen Händedesinfektion gehören medizinische Schutzhandschuhe zu den wichtigsten infektionsprophylaktischen Maßnahmen [3]. Sterile Handschuhe dienen dem Schutz von Personal und Patient [3]. Bei allen Maßnahmen am Patienten sollten Handschuhe geeigneter Qualität und Größe getragen werden. Operationshandschuhe sind sehr wichtig zum Schutz des medizinischen Personals vor pathogenen Keimen während der Operation, besonders bei übertragbaren Problemkeimen (HBV, HCV, HIV) [53, 53]. Nur intakte Handschuhe können schützen, perforierte nicht. Handschuhperforationen sind ein großes Problem und auch Bedrohung in der Chirurgie $[2,53,53]$. Operateur und Instrumentierende müssen sich klar sein: mit der Dauer der Operation steigt die Perforationsgefahr von Handschuhen. Am häufigsten sind betroffen der Zeigefinger der nicht dominanten Hand mehr als der dominanten, die nicht dominante Handinnenfläche und die Daumen $[51,39,60,79,81]$. Verständlich ist, dass die Handschuhe der Assistenten weniger Perforationen zeigen. Frappierend mag zuerst erscheinen, dass die Handschuhe von OP-Schwestern häufiger Perforationen $(61 \%)$ als die der Operateure (21\%) aufzeigen [81]. Dies wird insbesondere in der Gefäß- und Thoraxchirurgie beobachtet, während in Unfallchirurgie und Orthopädie die Situation umgekehrt erscheint [40]. Eine Erklärung mag sein, dass diese durch das Instrumentenhandling und die Manipulationen beim Einfädeln der Fäden in die Nadeln gefährdet sind [30].

Immer Handschuhe geeigneter Qualität und Größe tragen!

Verschiedene Autoren konnten zeigen, dass von benutzten Handschuhen bei allgemeinchirurgischen Operationen 6,4$7,8 \%$ perforiert waren bzw. dass in $18,3 \%$ aller Operationen Handschuhe perforiert wurden $[23,40]$. Bei Fußoperationen wurden in 23\% Handschuhperforationen beobachtet [47]. Die Einschränkung bei vielen Handschuhstudien ist, dass es sich überwiegend um „low risk“ chirurgische Disziplinen handelt [68].

Es sollten Handschuhe korrekter Größe und geeigneter Qualität getragen werden [35]. Zu große Handschuhe führen nicht nur zu schlechterer Taktilität, sondern stellen auch eine Gefährdung für das Personal dar (Abb.7): Beim Ausziehen der

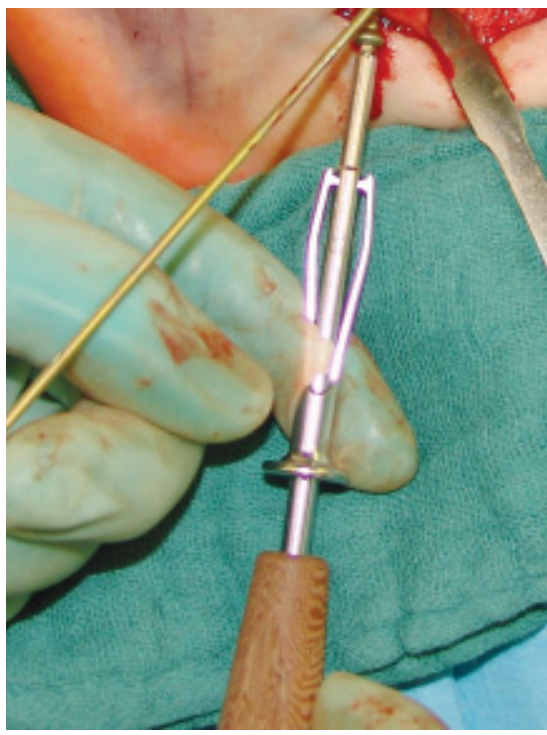

Abb.7 Handschuhe sollten genau passen. $\mathrm{Zu}$ kleine Handschuhe führen zu Durchblutungsstörungen, meist spürbar an Kribbeln der Fingerkuppen oder Schmerzen. Zu große Handschuhe stören die Empfindlichkeit und stellen eine Gefährdung dar, weil nicht anliegende Latexanteile sich einklemmen können wie hier in den Schraubehalter des Schraubenziehers.

Handschuhe sollte immer der Kontakt mit der äußeren beschmutzten bzw. kontaminierten Oberfläche vermieden werden, die Hände sind danach zu desinfizieren [35].

Doppelte Handschuhe - Indikatorsystem

Durch Verwendung von doppelten Handschuhen kann die Verletzung der Haut deutlich gesenkt werden. Für Operationen in Unfallchirurgie und Orthopädie werden doppelte Handschuhe empfohlen [3].

Indikatorhandschuhe zeigen kleinste Perforationen, die dem Nutzer sonst nicht auffallen (Abb.8a u.b). Intraoperativ konnten 36,84\% der Perforationen bei Einzellatexhandschuhen, aber $86,6 \%$ bei doppelten Latexhandschuhen (Indikatorsystem) entdeckt werden. In $82 \%$ aller Fälle schützt der äußere Handschuh den Chirurgen vor Kontamination [72]. Doppelte Handschuhe (zwei Paar sterile Handschuhe) reduzieren signifikant die Verletzung des inneren Handschuhs und damit die potenzielle Verletzungsgefahr des Operateurs [68]. Indikatorhandschuhe reduzieren zwar nicht die Gefahr von Perforationen gegenüber doppelten Latexhandschuhen, aber die Perforationen werden schneller durch die Grünverfärbung erkannt [68]. Wichtig ist, das OP- 

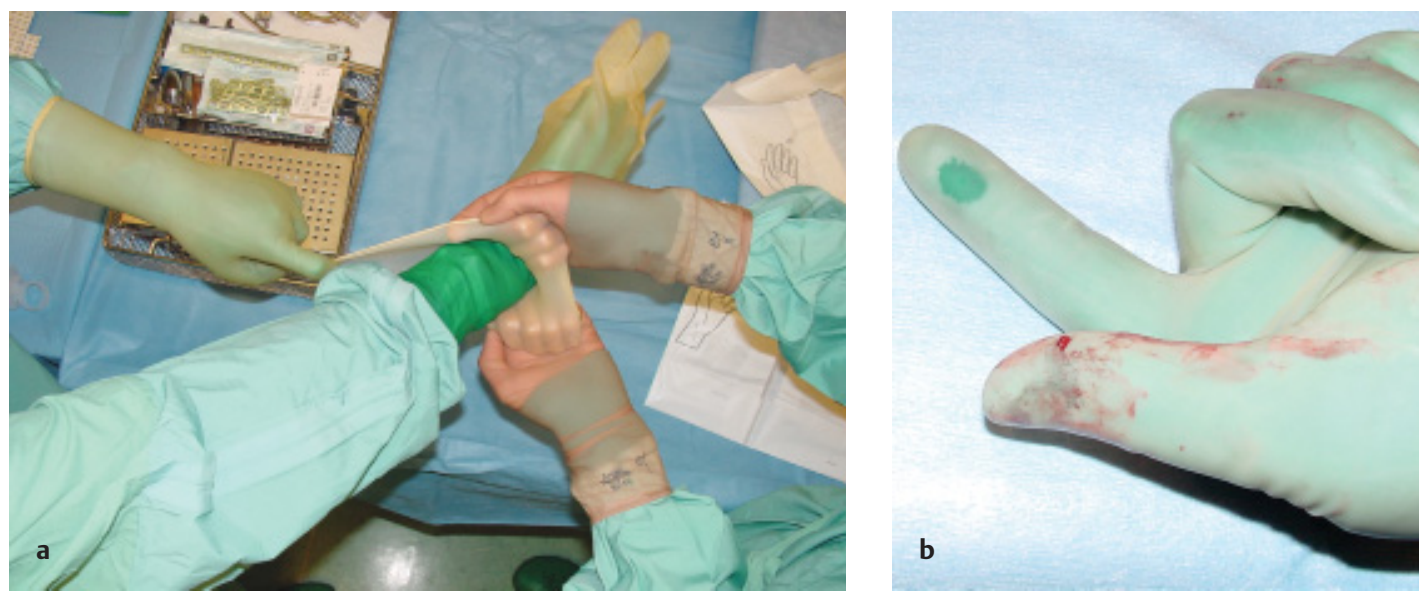

Abb. 8a, b Doppelte Handschuhe reduzieren erheblich die Verletzung der Haut. Indikatorhandschuhe bestehen aus einem grünen Latexhandschuh über den ein zweiter, dünner Handschuh gestreift wird. Bei Perforation verfärbt sich durch eintretende Flüssigkeit der Handschuh dunkelgrün: die Perforation ist nachgewiesen.

Handschuhe anderer Firmen mit dem Indikatorhandschuh meist erst verzögert reagieren, so dass trotz höherer Kosten die empfohlene Kombination des Indikatorsystems verwendet werden sollte.

Indikatorhandschuhe zeigen kleinste Perforationen, die dem Nutzer sonst nicht auffallen. Durch Verwendung von doppelten Handschuhen kann das Erkennen von Leckagen um 70-80\% erhöht werden.

Doppelte Handschuhe mit Indikatorsystem reduzieren die Rate der Blutkontamination von 13 auf $2 \%(\mathrm{p}<0,005)$ [52]. Der Vorteil von doppelten Handschuhen bzw. Indikatorhandschuhen wird aber häufig insbesondere von den Allgemeinchirurgen nicht genutzt (nur $28,2 \%$ ), während Orthopäden zu $72 \%$ diese verwenden [34,67]. Als Argumente werden angeführt schlechtere Taktilität und Preis. Obwohl gezeigt werden konnte, dass die 2-Punkte-Diskriminierung und auch die Fähigkeit zu knoten nicht abnimmt [77]. Der Erstautor empfiehlt, dass der Indikatorhandschuh eine halbe Nummer größer unter dem kleineren Außenhandschuh getragen wird. Wichtig ist weiterhin, dass der zweite Handschuh nicht zu stramm gezogen wird, um Durchblutungsprobleme der Fingerkuppen zu vermeiden. Der Chirurg und die OP-Pflegekraft sind also täglich Risikopatienten mit HBV-, HCV- oder HIV-Infektion ausgesetzt. Jeder Operateur sollte sich mit doppelten Handschuhen schützen $[40,52,72]$. Spezielle orthopädische dickere Operationshandschuhe scheinen ebenfalls resistenter gegen Stich- und andere Verletzungen zu sein [32], zeigen jedoch keinen Vorteil im Vergleich zur Verwendung von doppelten
Handschuhen. Während Knochenoperationen sollten regelmäßig alle 2 Stunden die Handschuhe gewechselt werden [43].

\section{Stoffhandschuhe}

Insbesondere bei unfallchirurgischen und orthopädischen Operationen, d.h. bei allen Operationen an Knochen, bei der Benutzung von Meißel und oszillierender Säge, sollten Stoffhandschuhe als äußere Schicht eingesetzt werden, sie reduzieren das Risiko von Perforationen deutlich [64,28,45,68] (Abb.9). Ob so genannte Glove liner (Netzgewebehandschuhe aus Polyester-, Kevlar- oder Edelstahlgewebe) das Risiko der Perforation der Handschuhe reduzieren, wird kontrovers diskutiert $[45,68,35]$. Bei diesen Handschuhkombinationen muss jedoch die Einschränkung der taktilen Fähigkeit beachtet werden und kommt häufig nicht in Frage. Bei nachgewiesener Infektion mit HCV, HBV oder HIV sollte die digitale

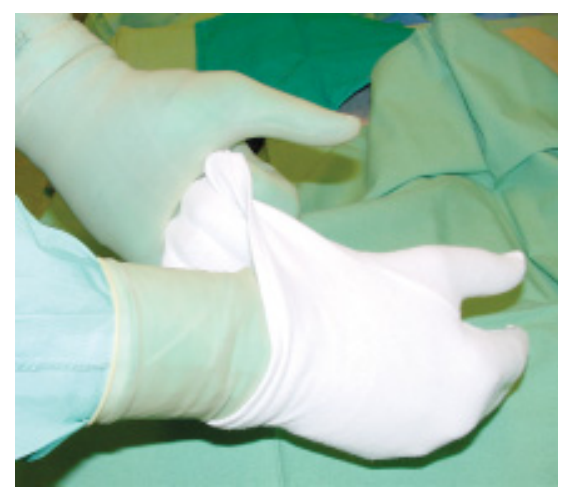

Abb.9 Baumwollhandschuhe reduzieren das Perforationsrisiko des Doppelhandschuhsystems bei Operationen am Knochen, beim Meißeln oder bei Cerclagedrähten. Die Baumwollhandschuhe sollen über den Latexhandschuhen getragen werden.
Überprüfung der Reposition nur mit zusätzlichen Stoffhandschuhen erfolgen (Abb.10a u.b).

\section{Unsterile Untersuchungshandschuhe}

Unsterile Handschuhe dienen dem Schutz des Personals [3]. Auch im perioperativen Bereich und in der Ambulanz sollte bei unsterilen Schutzhandschuhen bedacht werden, dass mit der Tragedauer die Perforationsgefahr steigt und dass Handschuhe minderer Qualität vermieden werden sollten [61]. Nur bei geringer mechanischer Beanspruchung sollten Vinylhandschuhe verwendet werden [35], bei sicher infizierten Patienten sollten diese nicht zum Einsatz kommen. Wenn Latex-Einmalhandschuhe verwendet werden, sollten ausschließlich puderfreie und allergenarme Produkte eingesetzt werden [82].

\section{Nadelkonfiguration, Skalpelle}

Auch der Einsatz stumpfer Nadelspitzen reduziert die Gefahr der Handschuhperforation erheblich [20]. Durch die spezielle Nadelspitzenkonfiguration konnte erreicht werden, dass die Nadel sich leicht durch Faszie, Muskel und Fettgewebe stechen lässt, jedoch nicht Haut und Operationshandschuhe penetriert [62]. Während der Operation sollte auch bei Skalpellklingen analog zu den Kanülen das Recapping vermieden werden, da hierbei die Verletzungsrate sehr hoch ist. Bei Risikopatienten sollten eher Einmalskalpelle verwendet werden.

\section{Operationskleidung}

Neben den Handschuhen erhöhen Waterproof-Operationskleidung und Gesichtsschutz den Schutz vor Kontamination [23]. Das Schutzkleidung [82], sprich 


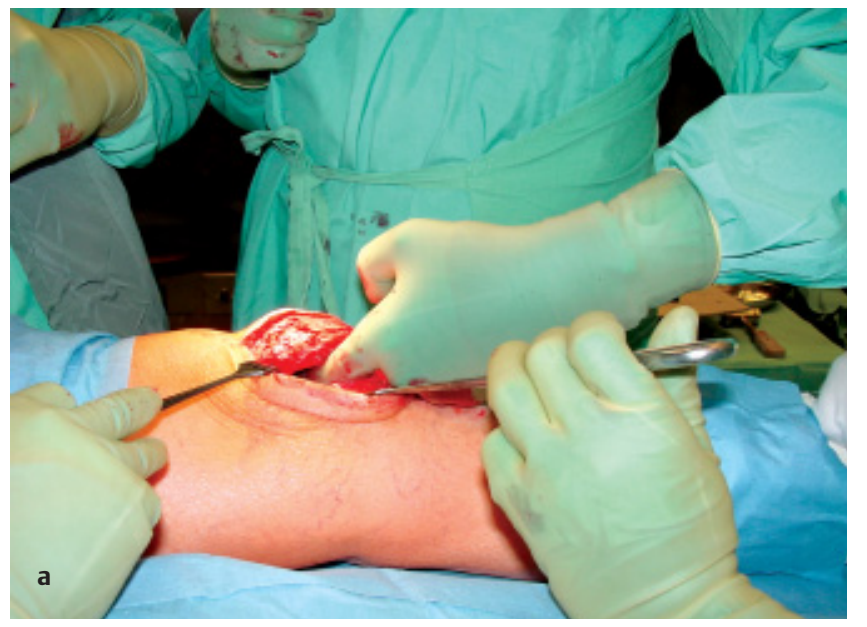

Abb.10a,b Bei Risikopatienten sollte nicht mit dem OPHandschuh alleine geschützt die Reposition überprüft werden wie hier bei einer Patellafraktur. Es sollte immer ein Zwirnhandschuh über den OP-Handschuhen verwendet werden, insbesondere bei Operationen an Becken und Azetabulum.

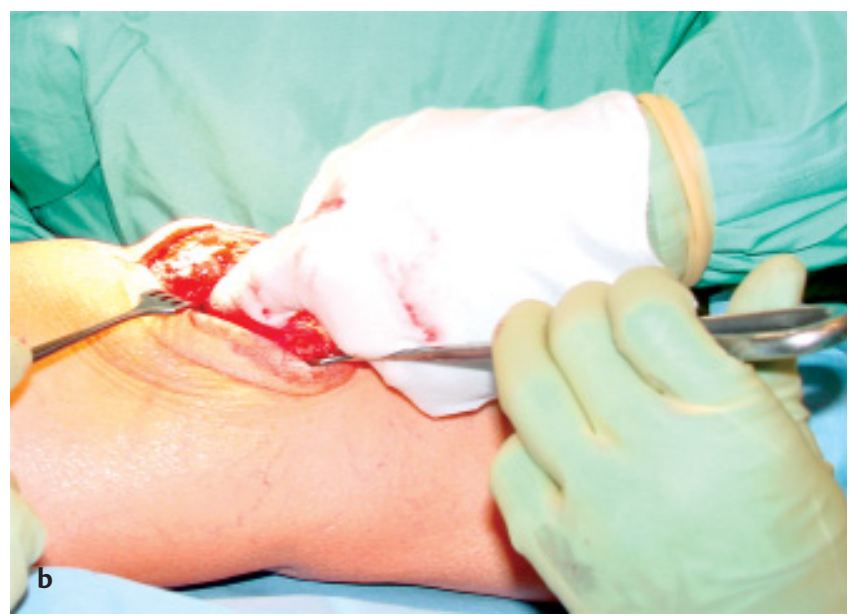

Operationskleidung und sterile Kittel, im OP getragen werden, muss nicht hervorgehoben werden. Das aber Aufenthaltsund Essräume mit Schutzkleidung nicht betreten werden dürfen [82], scheint nicht allen im OP klar zu sein.

\section{Gesichtsschutz/ \\ Schleimhautkontamination}

Bei Eingriffen, bei denen Blut, Körperflüssigkeiten verspritzt oder als Aerosole frei werden können, z.B. Jet-Lavage, Bohren, Fräsen sollten Spritzschutz, Gesichtsschild, Schutzbrille und Atemschutzmaske getragen werden [82], denn nur so kann die Inhalation der Erreger auf ein Minimum reduziert werden. Die transkonjunktivale Exposition als potenzielle Eintrittspforte für Hepatitisviren und HIV wird häufig vernachlässigt. Schutzbrillen sitzen oft nicht passgerecht, der Fluid-Shield der Masken reflektiert so stark, dass die Sicht beeinträchtigt ist (Abb.11). Unerwartet hohe Spritzereignisse treten unbemerkt auf, nicht nur bei HNO-Eingriffen [37]. Auch bei der Entscheidung eine Schutzbrille zu tragen, hilft das Screening, der Operateur muss die Schutzbrille nur bei auffälligem Screening tragen [19]. Eine individuell angepasste Schutzbrille führt durch den Tragekomfort zu einer wesentlich besseren Akzeptanz (Abb.12).

\section{Sofortmaßnahmen nach Kontakt mit infektiösem Material}

Eine besondere Infektionsgefahr besteht gegenüber HBV und HCV sowie HIV nach Hautdurchtritt von Gegenständen, Instrumenten, Knochen, die mit Blut oder Körperflüssigkeiten benetzt sind, insbesondere wenn:

- es zu einer tiefen Verletzung gekommen ist.

- Blut sichtbar am Gegenstand war.

- der Indexpatient eine hohe Viruslast hat.

- wenn Schleimhäute oder Haut mit offenen Läsionen mit Blut oder Körperflüssigkeit benetzt werden.

Nach Stich- und Schnittverletzungen sollte die Wunde sofort zur Blutung angeregt werden, außerdem hautverträgliche Desinfektion.

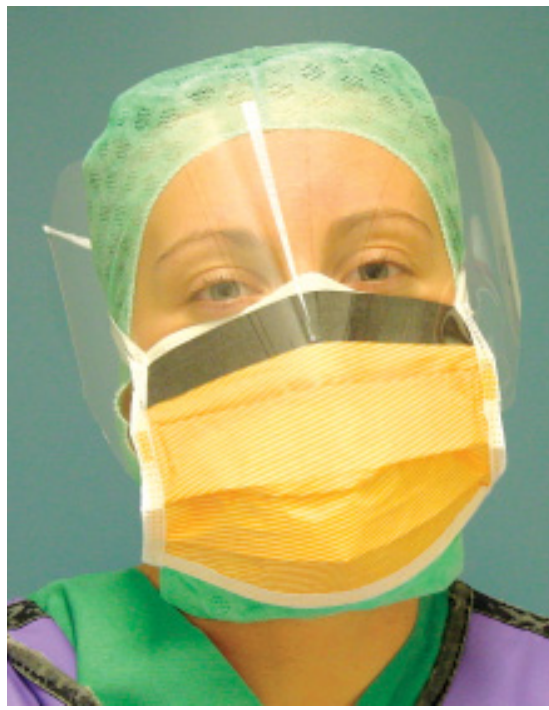

Abb.11 Gesichtsschildmasken verhindern direkten Kontakt von Körperflüssigkeiten mit den Augen. Bei Entstehung von Aerosolen (Jetlavage) kann der Schleimhautkontakt nicht komplett vermieden werden.

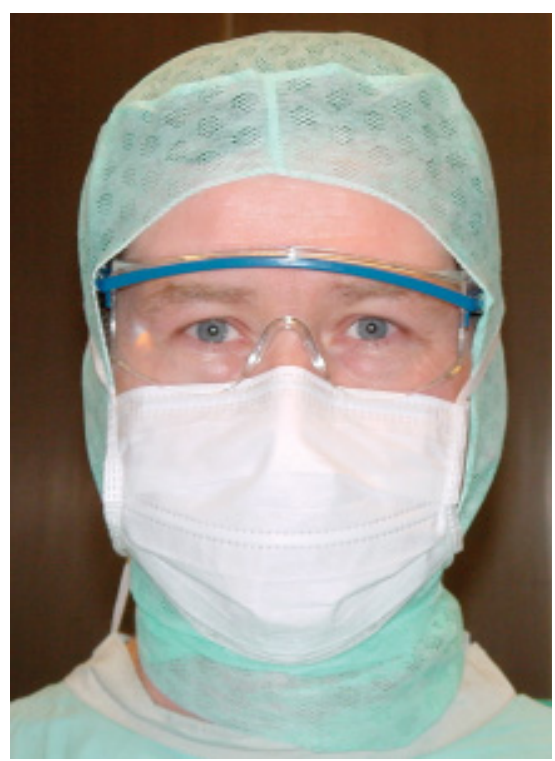

Abb.12 Adaptierbare oder individuelle Schutzbrillen liegen den Augen und der Stirn eng an, ermöglichen einen uneingeschränkten Blick auf das OP-Feld und bieten damit einen optimalen Schutz vor Schleimhautkontamination der Augen.

Bei Blut- oder Körperflüssigkeitkontakt auf vorgeschädigter oder ekzematöser Haut: Abspülen mit fließendem Wasser und hautverträgliche Desinfektion.

Bei Blut- und Körperflüssigkeit auf intakter Haut: Abspülen mit fließendem Wasser und hautverträgliche Desinfektion. Bei Kontakt mit But- oder Körperflüssigkeit auf Schleimhäuten: Spülung mit einem schleimhautverträglichen Desinfektionsmittel. 
Im Falle einer Verletzung sollte sofort nach der Verletzung durch Druck und Ausstreichen proximaler Gefäße zur Wunde hin bzw. durch Wundspreizung der Blutfluss angeregt und die Wunde mit einem alkoholischen Desinfektionsmittel für 10 Minuten desinfiziert und steril verbunden werden [82]. Bei Augenoder Mundschleimhautkontamination sollte sofort mit viel Wasser und/oder PVP-Jodlösung gespült werden. Da Ragaden und wunden Hautstellen mögliche Eintrittspforten für Krankheitserreger sind, sollte hierbei die Haut bei Kontamination desinfiziert werden [82]. Wichtig ist bei jeder Verletzung die Dokumentation im OP, die Vorstellung beim Durchgangsarzt (DA) und Meldung bei der Berufsgenossenschaft. Der Betriebsarzt (BA) ist zu informieren. Der DA oder der BA wird die erforderlichen Blutuntersuchungen (Anti-HBs, Anti-HCV und Anti-HIV) beim Verletzten und beim Patienten nach Zustimmung einleiten [21]. Ist der Patient nicht ansprechbar, wird von der SUVA aus Gründen des Arbeitnehmerschutzes (mögliche Gefährdung und versicherungstechnische Konsequenzen für die betroffenen Arbeitnehmenden) eine durch Blut übertragbare Infektion beim Indexpatienten nachzuweisen oder auszuschließen, - die Blutentnahme vorgenommen [35]. Die Wiederholung der Tests nach 6 und 12 Wochen, sowie 6 Monaten ist angezeigt [82]. Je nach Immunstatus von Verletztem und Patient sowie Verletzungsschwere wird die konkrete Gefährdung eingeschätzt.

Bei HBV-Kontakt sollte neben den o.g. Maßnahmen bei nicht ausreichendem Impfschutz sofort aktiv gegen HBV geimpft werden [82]. Innerhalb von 6 Stunden ist die passive Immunisierung zu beginnen [82]. Bei Kontakt mit Blut einer nachweislich Hepatitis-C-positiven Person sollte nach 2 Wochen eine HCV-PCR erfolgen, eine Frühtherapie einleiten zu können [82]. Nach HIV-Kontakt muss eine medikamentöse Postexpositionsprophylaxe (PEP) innerhalb von 2 Stunden nach der Verletzung begonnen werden $[83,58,13]$. Die PEP hat starke Nebenwirkungen. Indikationen und weitere Informationen können detailliert nachgelesen werden $[35,83,58,13]$, www.bgw.de, www.hivpep.ch, www.suva.ch, www.cdc.gov, www.osha-slc.gov.

Bei Infektionskrankheiten, die infolge von Nadelstichverletzungen o.ä. entstehen, handelt es sich um Berufskrankheiten im Sinn der gesetzlichen Unfallversicherung (Berufskrankheiten-Verordnung Nr. 3101).

\section{Auswirkungen einer Infektion auf das Personal}

Für den Operateur bzw. das Personal, dass sich infiziert hat, bedeutet die Infektion mit HBV, HCV oder HIV einen gravierenden Einschnitt in das Berufsleben. Denn, wenn infiziert, können diese beiden Gruppen ihre Patienten gefährden. Die Übertragungsmöglichkeit von HBV, HBC und HIV durch infiziertes Personal (nosokomiale Übertragung) ist bekannt $[25,26]$. Die Infektionsrate bei perkutaner Verletzung liegt bei HBV mit negativem HbeAg bei $2 \%$, mit positivem Nachweis von HbeAg bei $30-40 \%$, bei HCV zwischen 3 und $10 \%$ und für HIV mit perkutanem Kontakt bei 0,3\%, bei Schleimhautkontakt bei $0,3 \%[22,71]$. HbeAg-positive oder HIV-positive Chirurgen dürfen keine Tätigkeiten mehr an Patienten durchführen, die mit einem erhöhten Risiko für die Infizierung der Patienten einhergehen $[26,27]$, dies kommt für einen Chirurgen gleich einem Operations- bzw. einem Berufsverbot.

In Kanada müssen Mitarbeiter medizinischer Berufe mit positivem HBsAg-Nachweis und bei Nachweis von HBeAg ihre praktische Tätigkeit nämlich bei Tätigkeiten mit erhöhtem Übertragungsrisiko, sog. exposure-prone procedures [8], einstellen, bei der Patienten potenziell in Kontakt mit Körperflüssigkeiten kommen können, bis ihre weitere Tätigkeit von einem Gremium eingestuft wurde [4]. Ohne HbeAg-Nachweis wird ein Expertengremium in USA und Kanada die weitere ärztliche Tätigkeit erlauben $[4,17,17]$. Im Jahr 2000 erlaubten die britischen Leitlinien einem HCV-Ak positivem Chirurgen weiter Exposure-prone-Prozeduren durchzuführen, bis nachgewiesen war, dass er HCV auf einen Patienten übertragen hatte. Dies wurde begründet mit der niedrigen Übertragungsrate von $\mathrm{HCV}$ in Anlehnung für HBsAg-positive Chirurgen ohne HbeA-Nachweis [14].

Es ist die ärztliche Verantwortung und ethische Pflicht bei Kenntnis einer Selbstinfektion mit HBV, HCV oder HIV keine operativen Maßnahmen durchzuführen, bei denen das Risiko einer Übertragung auf den Patienten besteht [69]. Jedoch muss beachtet werden, dass bei den drei Viren unterschiedliche Virulenz besteht. Es muss individuell entschieden werden. Dass ein infizierter Chirurg seinen Patienten anstecken kann, ist gegenüber dem Risiko, dem der Chirurg durch den Patienten ausgesetzt ist, vernachlässigbar $[16,73]$. Wird ein ärztlicher oder
Pflegemitarbeiter im Dienst HCV, HBV oder HIV infiziert, so liegt eine Berufserkrankung (BK 3101) vor [16]. Kommt es zu einer fraglichen Übertragung vom Chirurgen auf den Patienten, so kann heute durch Genomanalyse geklärt werden, ob die Infektion tatsächlich durch den Operateur verursacht wurde [63].

\section{Fazit}

Gefahren bestehen im OP bei jeder Operation, insbesondere in der Unfallchirurgie und in der Orthopädie. Durch Präventionsmaßnahmen lässt sich das Risiko jedoch deutlich verringern. Besondere Vorsicht müssen Operateur und instrumentierende OP-Kraft walten lassen bei:

- Digitaler Überprüfung von Fragmenten, z.B. Beckenchirurgie

- Bei minimalinvasiven Eingriffen

- Bei Cerclagen

- Bei spitzen und scharfen Instrumenten

Bei Redonspießen

- Bei engem Operationsfeld

- Bei verlängerten Operationszeiten

Bei starken Blutungen

Die Akteure sollten:

- Keine Nadeln mit den Fingern fassen und tasten

- (doppelte) Indikatorhandschuhsysteme verwenden

- in der Knochenchirurgie und Prothetik Zwirnhandschuhe benutzen

- mit der Indikation zur Jet-Lavage zurückhaltend sein

- besondere Vorsicht bei der Entsorgung verwenden

\section{Erklärungen verwendeter Begriffe}

Prävalenz

Maß der Krankheitsfälle, die zu einem bestimmten Zeitpunkt bestehen oder in einem Zeitraum auftreten

\section{Inzidenz}

Zahl der Neuerkrankungen in einem definierten Zeitraum

\section{$H B V$}

Hepatitis-B-Virus, synonym verwendet für Hepatitits B-Infektion

\section{HCV}

Hepatitis-C-Virus, synonym verwendet für Hepatitits C-Infektion

\section{HIV}

human immunodeficiency virus 


\section{Literatur}

${ }^{1}$ Alter MJ. Epidemiology of hepatitis C. Hepatology 1997; 26: 62S-65S

${ }^{2}$ Alter MJ, Kruszon-Moran D, Nainan OV, McQuillan GM, Gao F, Moyer LA, Kaslow RA, Margolis HS. The prevalence of hepatitis C virus infection in the United States, 1988 through 1994. N Engl J Med 1999; 341: 556-562

${ }^{3}$ AWMF Arbeitskreis Hygiene in Klinik und Praxis, Empfehlungen zur Hygiene in Klinik und Praxis. Anforderungen an Handschuhe zur Infektionsprophylaxe im Gesundheitswesen. AWMF-Leitlinienregister 2004; $\mathrm{Nr}$. 029/021

${ }^{4}$ Barrigar DL, Flagel DC, Upshur RE. Hepatitis $B$ virus infected physicians and disclosure of transmission risks to patients: A critical analysis. BMC Med Ethics 2001; 2: 4

${ }^{5}$ Bell DM. Occupational risk of human immunodeficiency virus infection in healthcare workers: an overview. Am J Med 1997; 102: 9-15

${ }^{6}$ Beltrami EM, Williams IT, Shapiro CN, Chamberland ME. Risk and management of bloodborne infections in health care workers. Clin Microbiol Rev 2000; 13: 385-407

${ }^{7} \mathrm{bgw}$,Berufsgenossenschaft für Gesundheitsdienst und Wohlfahrtpflege Hamburg, Risiko Virusinfektion. 2003; M 612/613

${ }^{8}$ Botet X, Serra J, Padros R, Lopez S, Boldo E, Llaurado JM, Trias R, Rius X. Efficacy of $\mathrm{PdB}$ in preventing intraoperative risk of infectious diseases. World J Surg 1998; 22: $1092-1097$

${ }^{9}$ Caillot JL, Cote C, Abidi H, Fabry J. Electronic evaluation of the value of double gloving. $\mathrm{Br}$ J Surg 1999; 86: $1387-1390$

${ }^{10}$ Caillot JL, Cote C, Lemaire C, Fabry J. Electronic detection of breaks in the surgeon-patient barrier. Evaluation of protective clothing in visceral surgery]. Ann Chir 2000; 125: 358 - 362

${ }^{11} \mathrm{CDC}$, Recommendations for Preventing Transmission of Human Immunodeficiency Virus and Hepatitis B Virus to Patients During Exposure-Prone Invasive Procedures. 1991; 40

${ }^{12}$ CDC Centers for Disease Control and Prevention (CDC) Recommendations for follow-up of health-care workers after occupational e exposure to hepatitis C virus. Morbid Mortal Weekly Rep 1998; 47: 603-606

${ }^{13}$ CDC Centers for Disease Control and Prevention (CDC) Centers for Disease Control and Prevention: HIV/AIDS Surveillance Report 1999. 1999; 11: 1-44

${ }^{14}$ CDC Centers for Disease Control and Prevention (CDC) Updated U.S. Public Health Service Guidelines for the Management of Occupational Exposures to HBV HCV and HIV and Recommendations for Postexposure Prophylaxis. MMWR Recomm Rep 2001; 50: $1-52$

${ }^{15}$ Cockcroft A. Surgeons who test positive for hepatitis $C$ should not be transferred to low risk duties. Rev Med Virol 2000; 10: 79-82

${ }^{16}$ Corlett MP, England DW, Kidner NL, Attard $A R$, Fraser IA. Reduction in incidence of glove perforation during laparotomy wound closure by 'no touch' technique. Ann R Coll Surg Engl 1993; 75: 330-332

${ }^{17}$ Dietrich M. Berufsbedingte Infektionskrankheiten. Trauma und Berufskrankh 2001; 3: $152-155$

${ }^{18}$ Division of Nosocomial and Occupational Infections Bureau of Infectious Diseases. Laboratory Center for Disease Control. Health
Protection Branch. Health Canada. Proceedings of the Consensus Conference on Infected Health Care Worker Risk for transmission of bloodborne pathogens. Can Commun Dis Rep 1998; 24 Suppl 4: i-iii 1-25; i-iii $1-28$

${ }^{19}$ Dorevitch S, Forst L. The occupational hazards of emergency physicians. Am J Emerg Med 2000; 18: 300-311

${ }^{20}$ Dresing K, Pouwels C, Bonsack S, Oellerich M, Schworer H, Uy A, Sturmer KM. [HCV HBV and HIV infections: risk for surgeon and staff. Results and consequences of routine screening in emergency patients]. Chirurg 2003; 74: 1026-1033

${ }^{21}$ Edlich RF, Wind TC, Hill LG, Thacker JG, McGregor W. Reducing accidental injuries during surgery. J Long Term Eff Med Implants 2003: 13: $1-10$

${ }^{22}$ Fachausschuss "Gesundheitsdienst und Wohlfahrtspflege" der BGZ HVBG Hauptverband der gewerblichen Berufsgenossenschaften: Berufsgenossenschaftliche Regeln für sicherheit und Gesundheit bei der Arbeit BG Regel: Biologische Arbeitsstoffe im Gesundheitswesen und in der Wohlfahrtspflege. BGR 250/TRBA 2502003

${ }^{23}$ Gerberding JL. Management of occupational exposures to blood-borne viruses. N Engl J Med 1995; 332: 444-451

${ }^{24}$ Gerberding JL, Littell C, Tarkington A, Brown A. Schecter WP. Risk of exposure of surgical personnel to patients' blood during surgery at San Francisco General Hospital. N Engl J Med 1990; 322: 1788-1793

${ }^{25}$ Grady GF, Lee VA, Prince AM, Gitnick GL, Fawaz KA, Vyas GN, Levitt MD, Senior JR, Galambos JT, Bynum TE, Singleton JW, Clowdus BF, Akdamar K, Aach RD, Winkelman EI, Schiff GM, Hersh T. Hepatitis B immune globulin for accidental exposures among medical personnel: final report of a multicenter controlled trial. J Infect Dis 1978; 138: 625-638

${ }^{26}$ Hasselhorn HM, Hofmann F. [Nosocomial hepatitis B virus hepatitis $C$ virus and HIV infections by infectious medial personnel]. Gesundheitswesen 1998; 60: 545-551

${ }^{27}$ Hasselhorn HM, Hofmann F. [Transmission of HBV HCV and HIV by infectious medical personnel-presentation of an overview]. Chirurg 2000; 71: 389-395

${ }^{28}$ Heptonstall J. Surgeons who test positive for hepatitis $\mathrm{C}$ should be transferred to low risk duties. Rev Med Virol 2000; 10: 75 - 78

${ }^{29}$ Herscovici DJ, DiPasquale T, Sanders R. Comparison of cloth gloves used in orthopaedic surgery: a clinical and experimental evaluation. J Orthop Trauma 1998; 12: 106-110

${ }^{30}$ Hofmann F, Michaelis M, Rieger MA, Hasselhorn HM, Berthold H. [Occupational medicine significance of hepatitis $C$ in health care employees]. Gesundheitswesen 1997; 59: $452-460$

${ }^{31}$ Hussain SA, Latif AB, Choudhary AA. Risk to surgeons: a survey of accidental injuries during operations. Br J Surg 1988; 75: 314 - 316

${ }^{32}$ Ippolito G, Puro V, De CG. The risk of occupational human immunodeficiency virus infection in health care workers. Italian Multicenter Study. The Italian Study Group on Occupational Risk of HIV infection. Arch Intern Med 1993; 153: 1451 - 1458

${ }^{33}$ Jackson EM, Neal JG, Williams FM, Stern CA, Suber F, Thacker JG, Edlich RF. Biomechanical performance of orthopedic gloves. J Biomed Mater Res 1999; 48: 193-198

${ }^{34}$ Janssen RS, St.Louis ME, Satten GA, Critchley SE, Petersen LR, Stafford RS, Ward JW, Han- son DL, Olivo N, Schable CA et a. HIV infection among patients in U.S. acute care hospitals. Strategies for the counseling and testing of the hospital patients. The Hospital HIV Surveillance Group. N Engl J Med 1992; 327: $445-452$

${ }^{35}$ Johanet H, Tarantola A, Bouvet E. [Protection methods in the operating room and risks of blood exposure. Results of a national survey]. Ann Chir 2000; 125: 385-390

${ }^{36}$ Jost M, Francioli P, Iten A, Jost J. Colombo C Cartier B Rüegger M Gutzwiller A Verhütung blutübertragbarer Infektionen im Gesundheitswesen. 2003: 11

${ }^{37}$ Kelen GD, Green GB, Purcell RH, Chan DW, Oaqish BF, Sivertson KT, Quinn TC. Hepatitis $\mathrm{B}$ and hepatitis $\mathrm{C}$ in emergency department patients. N Engl J Med 1992; 326: 1399 1404

${ }^{38}$ Keogh IJ, Hone SW, Colreavey M, Walsh M. Blood splash and tonsillectomy: an underestimated hazard to the otolaryngologist. J Laryngol Otol 2001; 115: 455-456

${ }^{39}$ Kirsch U. Handschuhschonende Op-Techniken und doppelte Behandschuhung aus der Sicht der BG in: (HRSG.:) Hofmann F, Kralj N, Schwarz TF: Technischer Infektionsschutz im Gesundheitsdienst II Anwendung doppelter Handschuhe.

${ }^{40}$ Kralj N, Beie M, Hofmann F. Chirurgische Handschuhe - wie gut schützen sie vor Infektionen. Gesundheitswesen 1999; 61: $398-403$

${ }^{41}$ Laine T, Aarnio P. How often does glove perforation occur in surgery? Comparison between single gloves and a double-gloving system. Am J Surg 2001; 181: 564-566

${ }^{42}$ LaPorte DM, Mont MA, Jones LC, Padden DA, Hungerford DS. Human immunodeficiency virus testing for elective orthopedic procedures: results in a community-based hospital. Orthopedics 2001; 24: $52-55$

${ }^{43}$ Laufs R, Polywka S, Feucht HH, Schroter M, Zollner B, Oehler G. [Hepatitis C. Virology transmission modes clinical aspects prevention and therapy]. Anaesthesist 2002; 51: $884-889$

${ }^{44}$ Liew SM, Stoney JD, Falkenberg MP, Leitl SM. A comparative study of two types of latex surgical gloves in elective orthopaedic surgery. Aust N Z J Surg 1995; 65: 406-408

${ }^{45}$ Louie M, Low DE, Feinman SV, McLaughlin B, Simor AE. Prevalence of bloodborne infective agents among people admitted to a Canadian hospital. CMAJ 1992; 146: 1331 -1334

${ }^{46}$ Louis SS, Steinberg EL, Gruen OA, Bartlett CS, Helfet DL. Outer gloves in orthopaedic procedures: a polyester/stainless steel wire weave glove liner compared with latex. J Orthop Trauma 1998; 12: $101-105$

${ }^{47}$ Lowenfels AB, Wormser GP, Jain R. Frequency of puncture injuries in surgeons and estimated risk of HIV infection. Arch Surg 1989; 124: $1284-1286$

${ }^{48}$ Maffulli N, Testa V, Capasso G. Glove perforation in foot surgery. Foot Ankle 1991; 11 $228-230$

${ }^{49}$ Marcus R, Kay K, Mann JM. Transmission of human immunodeficiency virus (HIV) in health-care settings worldwide. Bull World Health Organ 1989; 67: 577-582

${ }^{50}$ McGrory BJ, Kilby AE. Hepatitis C virus infection: review and implications for the orthopedic surgeon. Am J Orthop 2000; 29: 261 266

${ }^{51}$ Mineiro J, Catela A, Pedro M, Gouveia A, Gomes AR. [The risk of seroconversion in surgeons of the hepatitis B hepatitis C and human immunodeficiency viruses (in a specific 
surgical population)]. Acta Med Port 1997; 10: $455-461$

${ }^{52}$ Murta EF, Silva CS, Junior OR. Frequency of glove perforation and the protective effect of double gloves in gynecological surgery. Arch Gynecol Obstet 2003; 268: $82-84$

${ }^{53}$ Naver LP, Gottrup F. Incidence of glove perforations in gastrointestinal surgery and the protective effect of double gloves: a prospective randomised controlled study. Eur J Surg 2000; 166: 293-295

${ }^{54}$ Osman MO, Jensen SL. Surgical gloves: current problems. World J Surg 1999; 23: 630 7; discussion 637

${ }^{55}$ Palitzsch KD, Hottentrager B, Schlottmann K, Frick E, Holstege A, Scholmerich J, Jilg W. Prevalence of antibodies against hepatitis $C$ virus in the adult German population. Eur J Gastroenterol Hepatol 1999; 11: $1215-1220$

${ }^{56}$ Palmer JD, Rickett JW. The mechanisms and risks of surgical glove perforation. J Hosp Infect 1992; 22: 279-286

${ }^{57}$ Panlilio AL, Foy DR, Edwards JR, Bell DM, Welch BA, Parrish CM, Culver DH, Lowry PW, Jarvis WR, Perlino C. A Blood contacts during surgical procedures. JAMA 1991; 265: 1533-1537

${ }^{58}$ Panlilio AL, Shapiro CN, Schable CA, Mendelson MH, Montecalvo MA, Kunches LM, Perry SWr, Edwards JR, Srivastava PU, Culver DH et a. Serosurvey of human immunodeficiency virus hepatitis $B$ virus and hepatitis $C$ virus infection among hospital-based surgeons. Serosurvey Study Group. J Am Coll Surg 1995; 180: $16-24$

${ }^{59}$ Patel D, Gawthrop M, Snashall D, Madan I. Out of hours management of occupational exposures to blood and body fluids in healthcare staff. Occup Environ Med 2002; 59: $415-418$

${ }^{60}$ Patz JA, Jodrey D. Occupational health in surgery: risks extend beyond the operating room. Aust N Z J Surg 1995; 65: 627-629

${ }^{61}$ Pietrabissa A, Merigliano S, Montorsi M Poggioli G, Stella M, Borzomati D, Ciferri E, Rossi G, Doglietto G. Reducing the occupational risk of infections for the surgeon: multicentric national survey on more than 15000 surgical procedures. World J Surg 1997: 21: 573 - 578

${ }^{62}$ Pitten FA, Herdemann G, Kramer A. The Integrity of Latex Gloves in Clinical Dental Practice. Infection 2000; 6: 388-392

${ }^{63}$ Rice JJ, McCabe JP, McManus F. Needle stick injury. Reducing the risk. Int Orthop 1996; 20: $132-133$
${ }^{64}$ Ross RS, Viazov S, Roggendorf M. Phylogenetic analysis indicates transmission of hepatitis $C$ virus from an infected orthopedic surgeon to a patient. J Med Virol 2002; 66: $461-467$

${ }^{65}$ Sanders R, Fortin P, Ross E, Helfet D. Outer gloves in orthopaedic procedures. Cloth compared with latex. J Bone Joint Surg Am 1990; 72: 914-917

${ }^{66}$ Schreier E, Radun D, Neuhauser H, Stark K, Hepatitis C. in RKI (Hrsg.:) Gesundheitsberichterstattung des Bundes Themenhefte 2003 (ISBN 3-89606-143-7) 2003; Heft 15

${ }^{67}$ Shapiro CN, Tokars JI, Chamberland ME. Use of the hepatitis-B vaccine and infection with hepatitis $B$ and $C$ among orthopaedic surgeons. The American Academy of Orthopaedic Surgeons Serosurvey Study Committee. J Bone Joint Surg Am 1996; 78: 1791 -1800

${ }^{68}$ St. Germaine RL, Hanson J de GCJ. Double gloving and practice attitudes among surgeons. Am J Surg 2003; 185: 141 - 145

${ }^{69}$ Tanner J, Parkinson H. Double gloving to reduce surgical cross-infection. Cochrane Database Syst Rev 2002; 3: CD003087

${ }^{70}$ Tereskerz PM, Pearson RD, Jagger J. Infected physicians and invasive procedures: national policy and legal reality. Milbank Q 1999; 77: $511-29$ iii

${ }^{71}$ Thierfelder W, Meisel H, Schreier E, Dortschy R. [Prevalence of antibodies to hepatitis A hepatitis B and hepatitis $C$ viruses in the German population]. Gesundheitswesen 1999; 61 Spec No: S110-4

${ }^{72}$ Thomas DL, Gruninger SE, Siew C, Joy ED, Quinn TC. Occupational risk of hepatitis C infections among general dentists and oral surgeons in North America. Am J Med 1996; 100: $41-45$

73 Thomas S, Agarwal M, Mehta G. Intraoperative glove perforation-single versus double gloving in protection against skin contamination. Postgrad Med J 2001; 77: 458 - 460

74 Thomssen R. [Hepatitis B. The HBV-infected surgeon-risk of infection for the patient]. Chirurg 2002; 73: 435-438

${ }^{75}$ Thorburn D, Dundas D, McCruden EA, Cameron SO, Goldberg DJ, Symington IS, Kirk A, Mills PR. A study of hepatitis C prevalence in healthcare workers in the West of Scotland. Gut 2001; 48: 116-120

${ }^{76}$ Twitchell KT. Bloodborne pathogens. What you need to know-Part I. AAOHN J 2003; 51: 38 - 45; quiz 46-7

${ }^{77}$ van d EME Regez RM, Schreij G, van d MJT Danner SA. Post-exposure prophylaxis. Int J STD AIDS 2002; 13 Suppl 2: 30-34
${ }^{78}$ Webb JM, Pentlow BD. Double gloving and surgical technique. Ann R Coll Surg Engl 1993; 75: 291 - 292

${ }^{79}$ Weber B, Rabenau H, Berger A, Scheuermann EH, Staszewski S, Kreuz W, Scharrer I, Schoeppe W, Doerr HW. Seroprevalence of HCV HAV HBV HDV HCMV and HIV in high risk groups/Frankfurt a.M. Germany. Zentralbl Bakteriol 1995; 282: $102-112$

${ }^{80}$ Weber LW. Evaluation of the rate location and morphology of perforations in surgical gloves worn in urological operations. Appl Occup Environ Hyg 2003; 18: 65-73

${ }^{81}$ WHO WHO Health Data 2002 - Indikatoren des Gesundheitswesens. WHO regional office for Europe Copenhagen Denmark 2002

${ }^{82}$ Williams I. Epidemiology of hepatitis C in the United States. Am J Med 1999; 107: 2S-9S

${ }^{83}$ Wong PS, Young VK, Youhana A, Wright JE. Surgical glove punctures during cardiac operations. Ann Thorac Surg 1993; 56: 108 - 110

Univ.-Prof. Dr. med. K. M. Stürmer Direktor

Priv.-Doz. Dr. med. Klaus Dresing

Geschäftsführender Oberarzt

Klinik für Unfallchirurgie, Plastische und Wiederherstellungschirurgie Universitätsklinikum Göttingen

Georg-August-Universität

Stiftung Öffentlichen Rechts

Robert-Koch-Str. 40

D-37075 Göttingen

\section{Bianca Lumpp}

Fachkrankenschwester

für Operationsdienst

Bereichsleitung Unfallchirurgie/ Orthopädie, Zentral-OP

Universitätsklinikum Göttingen

Georg-August-Universität

Stiftung Öffentlichen Rechts

Robert-Koch-Str. 40

D-37075 Göttingen 